\title{
RELATIONSHIP BETWEEN INWARD FOREIGN DIRECT INVESTMENT, DOMESTIC INVESTMENT, FORMALAND INFORMAL INSTITUTIONS: EVIDENCE FROM CHINA
}

\section{Waqar Ameer, Helian Xu}

(1) School of Economics and Trade, Hunan University, Yuelushan, Changsha, Hunan Province, People's Republic of China

(2) School of Economics and Trade, Hunan University Yuelushan, Changsha, Hunan Province, People's Republic of China

Waqar Ameer

School of Economics and Trade, Hunan University Yuelushan, Changsha, Hunan Province, People's Republic of China waqar.ameer@yahoo.com

Article info Paper category: Original Scientific Paper Received: 4.7.2017. Accepted: 25·7.2017. JEL classification: $\mathrm{C}_{22}, \mathrm{~F}_{21}, \mathrm{O}_{10}$ 


\begin{abstract}
This study examines relationship between Inward FDI and domestic investment in China, using co-integration and Granger causality analysis (Including bivariate and multivariate Granger causality models). We have used auto-regressive distributed lags(ARDL) econometric methodology technique to define relationship between inward FDI and domestic investment using time series data for China. Our study examines long run effects of FDI inflows on domestic investment over time span 1990-2014 for China using informal, formal institutions and key macroeconomic variables as control variables in the model. The results suggest that conclusions drawn from bivariate model may not be valid because of omission of important control variables. Our results of multivariate model show that there is positive unidirectional causality running from IFDI to DI in the long run. In the short run, both inward FDI and domestic investment do not allow Granger causality.
\end{abstract}

\title{
Keywords:
}

Inward FDI; Domestic Investment; Cointegration; Time Series Data 


\section{INTRODUCTION}

Since FDI in global economy are the most important form of international business activity and investment is a key factor of economic development, analysis of the impact of FDI on domestic investment is theoretically justified (Derado, 2013). Foreign direct investment (IFDI) inflows has increased US\$2.002 trillion in 2007 in the world as compared to US\$ $13.34,6$ billion in 1970 (UNCTAD, 2013). The relationship between FDI inflows and domestic investment (DI) is still controversial. Some studies such as Xu and Wang (2007) and Chang (2010) found that FDI inflows have crowded in DI while some studies such as Adams (2009) found that FDI inflows have crowded out DI. Sağlam and Yalta (2011) found that there was no relationship between FDI inflows and DI. Some studies such as Agosin and Machado (2005) and Wang (2010) found that FDI inflows have had neutral, crowding-in effect or crowding-out effect on DI depending on country/country group economic structure, macro-economic environment, and the firm's underlying motives to invest abroad. The macroeconomic relationship between FDI inflows and DI are theoretically inconclusive and thus become an empirical issue. The effects of FDI on domestic investment is controversial issue and still inconclusive. Some research studies conclude that foreign direct investment reduces domestic investment, while some proportion of studies find that FDI are positively associated with domestic investment and some find no effect.

China is the largest transition economy and the second highest FDI recipient in the world. Using foreign investment to improve its international competitiveness is a major pillar of China's reform and "open-door" policy (Fukasaku \& Wall, 1994; Lardy, 1994; Naughton, 1997; Buckley, Clegg, \& Wang, 2006). Since its reform and "open-door" policy was implemented in 1978, China has attracted FDI globally and has become one of the world's largest FDI destinations. In last two decades, there has been a dramatic increase in FDI inflows and outflows in China, following the 1999 implementation of national policy encouraging DI to "go out". Lee, Syed, and Liu (2013) suggest that the Chinese growth model is highly dependent on the accumulation of DI. Best to our knowledge, no previous studies have measured long run effects of FDI inflows (IFDI) on domestic investment (DI) for China using formal institutions, informal institutions and key macroeconomic variables as control variables in the model. Thus, we bridge the gap in previous research literature by adding formal and informal institutions as key control variables in the model to measure role of institutions in defining accurate relationship between FDI inflows and domestic investment in the economy. Thus, this will be the contribution of our research study.

Our study contributes to the existing research literature by conduct analyses using a macroeconomic perspective to investigate the impact of FDI inflows on DI in China. To the best of our knowledge, no previous research studies have analyzed the impact of FDI inflows on DI at the macro-economic level in the case of China using bivariate and multivariate models. You and Solomon (2015) analyzed the impact 
of FDI outflows on DI in China using industry-level data. Here, we will bridge this shortcoming in the existing literature by analyzing the effect of FDI inflows on DI at the macroeconomic level by introducing new and interesting findings on the particular case of China. Therefore, this study addresses this question with the data of top highest recipient of FDI inflows Asian economy: China. Figure 1. provides a time series plot of China's DI (\%GDP) measured as Gross capital formation (\%GDP) over the time period 1990 to 2014. Figure 2. provides a time series plot of China's net inflows of FDI as measured as a percentage of GDP over the time period 1990 to 2014 .

Figure 1.: Time series plot of China's domestic investment measured as percentage of GDP

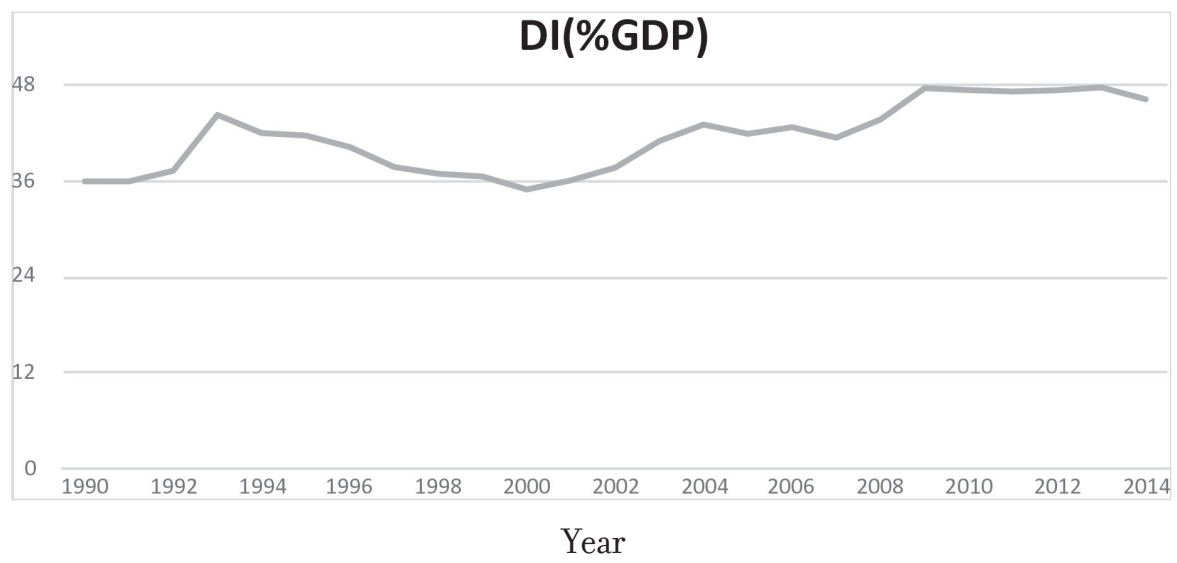

Source: World Development Indicators online (www.worldbank.org)

Figure 2.: Time series plot of China's net inflows of foreign direct investment measured as percentage of GDP

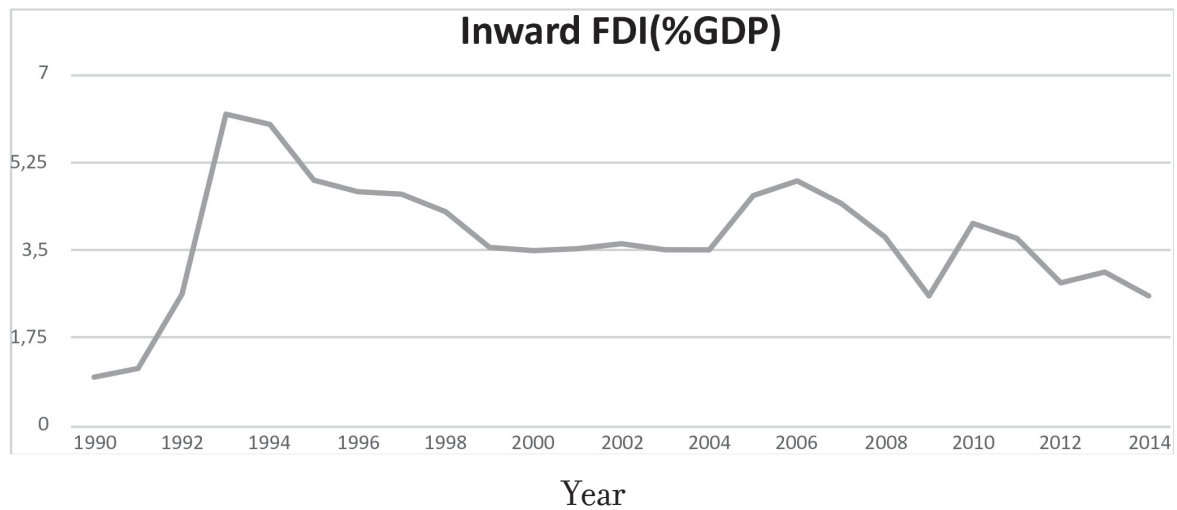

Source: United Nations Conference on Trade and Development (www.unctad.org)

The rest of the paper is presented as follows. Section 2. Literature review, Section 3. describes the data sources and econometric methodologies. Section 4. presents result findings of the analysis. Section 5 concludes the paper. 


\section{LITERATURE REVIEW}

Lean and Tan (2010) analyze relationships between FDI, Domestic investment and Economic growth in Malaysia and these three variables are cointegrated in the long-run in this study. Annual time series data from 1970 to 2009 were used and Vector autoregressive (VAR) methodology is applied. The empirical results of this study show that an increase of FDI will bring positive impact to the domestic investment. In simple words, FDI crowds in domestic investment and there appears complementary effect from FDI to domestic investment.

Prasanna (2010) analyze directand indirectimpact of FDI on domesticinvestment in India. Prasanna (2010) covered 16-year period from 1991-92 to 2006-07. This study finds that the direct impact of FDI inflows on domestic investment in Indiais positivebuttheindirectimpactis neutral' onthedomesticinvestmentinthe long run. The study finds no evidence that increase in domestic investment due to FDI inflows is greater than the amount of the FDI inflows in India. Bayraktar and Yalta (2011) found relationship among FDI, private domestic investment and public domestic investment in Turkey. They considered period from 1970 to 2009 using annual data incorporated into multivariate VAR framework. Their findings indicate that there is no longrun relationship between FDI, public investment and private investment, indicating the poor contribution of FDI to the Turkish investment path. The lack of interaction between FDI and domestic investment, which impedes the contribution of FDI to economic growth from capital accumulation channel, questions the benefits of FDI.

The effects of FDI on domestic investment has been analyzed by many studies for developing countries. Reviews by AL-Sadig (2013) and Arndt et al (2007) conclude that these studies use macro-level data or firm level data and their effects been positive, negative or neutral, thus overall results are inconclusive. Recent studies by Hejazi and Pauly (2003); Arndt et al. (2007) and Al-Sadig (2013) recommend that combination of home and foreign production may cause different potential effects by FDI outflows on domestic investment, depending on the motives for overseas investment. Referring to four OFDI motives i.e. (resource seeking, marketing seeking, efficiency-seeking and strategic asset seeking) identified by Dunning (1993), they point out that outward FDI may influence domestic investment positively or negatively or neutrally. Given that financial resources are scarce and financial markets are imperfect, domestic markets will have less financial liquidity available to fund new investment projects. The negative effects of outward FDI on domestic investment would be strong if availability of capital is scarce and capital outflows are financed internally. However, in countries where saving is abundant, the negative impact of outward FDI on domestic investment may be offset or may not be evident. 


\section{DATAAND METHODOLOGY}

In this study, we have used net IFDI ( $\%$ GDP), Trade Openness ( $\%$ GDP), gross capital formation (GCF), GDP deflator, and Gross domestic savings (\%GDP). Gross domestic savings (SAVINGS), export (EX), import (IM), GCF and trade openness (OPEN) are measured at current US\$. Annual data from 1990 to 2014 are obtained from UNCTAD FDI database. The starting period of this dataset is determined by the earliest availability date of the data. The sum of EX and IM divided by GDP is used as a proxy for trade openness (OPEN). The proxy for DI (\%GDP) is defined as GCF (\% GDP). We are using economic freedom (EF) as a proxy for formal institutions. Economic freedom data is taken from Fraser institute, economic freedom of the world. In this study, I have used net IFDI (\% GDP), gross capital formation (GCF) as percentage of GDP, and Trade (\% GDP). Annual data from 1990 to 2014 are obtained from World Development Indicators, World Bank Database. The starting period of this dataset is determined by the earliest availability date of the data. We are using gross capital formation (GCF) as proxy for domestic investment (DI). Following the previous research studies, this study constructs index of CULTURE by applying principle component analysis (PCA) using four basic components trust, respect, obedience and self-determination. We are using CULTURE proxy for informal institutions. Data is available in five waves spanning from 1990 to 2014, where single wave reflect average of five years for country's economic culture's value. These components are taken from WorldValues Survey (WVS) Database and are considered important in shaping human behavior especially economic behavior.

We use the bounds testing approach to co-integration developed by Pesaran, Shin and Smith (2001) to test for the existence of a long-run relationship. This test is based on the autoregressive distributed lag (ARDL) framework. It is used here because Pesaran and Shin (1999) show that the ordinary least squares (OLS) estimators of ARDL parameters are $\sqrt{ } n$-consistent, where $n$ is the sample size and the estimators of the long-run coefficients are super-consistent in small sample sizes. Furthermore, this approach can be used irrespective of whether the variables are integrated of $I(1), I(0)$, or mutually co-integrated. Many unit root tests are available. In this study, we have used only two of them, the augmented Dickey and Fuller (1979, 1981) test (ADF test) and the test proposed by Kwiatkowski et al. (1992; KPSS test). The null hypothesis of the ADF test is that a series is non-stationary, whereas the null hypothesis of the KPSS test is that a series is stationary. Both tests are performed with intercepts and time trends. The number of lags in the ADF test is selected based on the Schwarz Information Criterion. The choice of bandwidth parameter in the Bartlett kernel based sum-of-covariance estimator in the KPSS test is selected based on the Newey-West data-based automatic bandwidth parameter method. The results of the unit root tests are reported in Table 1 . Both the ADF and KPSS tests suggest that DI, EF, OPEN, CULTURE and SAVINGS are I(1). The results of the unit root tests for 
ADF and KPSS suggest that IFDI is I(o). Both the ADF and KPSS test results suggest that some variables are integrated of $I(0)$ or $I(1)$ respectively.

These control variables (EF, OPEN, CULTURE, SAVINGS) are chosen based on existing empirical work. Some research studies have also highlighted the effects of trade openness (OPEN) on DI. OPEN is expected to have a positive impact on DI through technology and knowledge spillover. However, it may also exert a negative impact on DI if consumers prefer imported products (Ndikumana, 2000). Alabdeli (2005) analyzed the effects of several macroeconomic variables (i.e., exports, investment) on economic growth in 21 developing countries, using time series data from 1960 to 2001 . This study concluded that DI has a positive and significant relationship with economic growth. Frankel (1997) analyzed the impact of economic factors, including investment in the public and private sector, on economic growth in East Asian economies. This study concluded that investment is among the most important determinants of economic growth in the long run.

\section{RESULTS}

To avoid the problem associated with conflicting results provided by conventional unit root tests-such as those found by Dickey and Fuller (1979, 1981) and Kwiatkowski, Phillips, Schmidt and Shin (1992), in this study when these tests are used jointly, we use the ARDL testing approach for co-integration. Firstly, we consider only the bivariate long-run relationship between IFDI and DI. Then, four additional variables (i.e., EF, OPEN, CULTURE and SAVINGS) are added as control variables in the model to find long-run relationship between IFDI and DI in order to capture country-specific effects.

Table 1.: Results of the unit root tests.

\begin{tabular}{|l|r|r|r|r|}
\hline \multicolumn{3}{|c|}{ ADF } & \multicolumn{2}{c|}{ KPSS } \\
\hline & Level & $\begin{array}{c}\text { First } \\
\text { Difference }\end{array}$ & \multicolumn{1}{c|}{ Level } & $\begin{array}{c}\text { First } \\
\text { Difference }\end{array}$ \\
\hline IFDI & $-4.2428^{* * * *}[1]$ & $-3.8632^{* * *}[1]$ & $0.1046[2]$ & $0.2221[2]$ \\
DI & $-1.3134[0]$ & $-4.1700^{* * *}[0]$ & $0.5101^{* *}[3]$ & $0.0769[0]$ \\
EF & $-1.4179[0]$ & $-5.2849^{* * * *}[0]$ & $0.662^{* *}[3]$ & $0.2564[5]$ \\
OPEN & $-1.5704[0]$ & $-3.8688^{* * *}[0]$ & $0.4567^{* *}[3]$ & $0.1607[1]$ \\
GULTURE & $-1.6522[0]$ & $-4.5885^{*}[0]$ & $0.1787^{* *}[3]$ & $0.3144[0]$ \\
SAVINGS & $-1.5101[1]$ & $-3.1568^{* *}[0]$ & $0.5632^{* *}[3]$ & $0.0888[2]$ \\
\hline
\end{tabular}

Source: Authors' calculation

Note: ${ }^{*}, * *$, and ${ }^{* * *}$ indicate statistical significance at the $10 \%, 5 \%$, and $1 \%$ levels, respectively. Values in square brackets are either the number of lagged first differences used in the ADF test or the choice of bandwidth parameter in the Bartlett kernel-based sum-of-covariances estimator in the KPSS test. The number of lags were selected based on the Schwarz Information Criteria. 
ADF: augmented Dickey and Fuller test; KPSS: Kwiatkowski-Phillips-Schmidt-Shin test; IFDI: inward foreign direct investment; DI: domestic investment; EF: economic freedom; OPEN: trade openness; SAVINGS: gross domestic savings.

In the bivariate model, the bounds test examines whether a long-run relationship exists in one of the following unrestricted error correction models:

$$
\begin{aligned}
\Delta \mathrm{IFDI}_{t} & =a_{0}+\sum_{i=1}^{n} a_{G i} \Delta \mathrm{IFDI}_{t-i}+\sum_{i=0}^{n} a_{F i} \Delta \mathrm{DI}_{t-i}+a_{1} \mathrm{IFDI}_{t-1}+a_{2} \mathrm{DI}_{t-1}+\varepsilon_{1 t} \\
\Delta \mathrm{DI}_{t} & =b_{0}+\sum_{i=1}^{n} b_{F i} \Delta \mathrm{DI}_{t-i}+\sum_{i=0}^{n} b_{G i} \Delta \mathrm{IFDI}_{t-i}+b_{1} \mathrm{DI}_{t-1}+b_{2} \mathrm{IFDI}_{t-1}+\varepsilon_{2 t}
\end{aligned}
$$

In equation ( 1 ), the null hypothesis of no co-integration amongst the variables is $\mathrm{H}_{\mathrm{o}}: \mathrm{a}_{1}=\mathrm{a}_{2}=0$ against the alternative hypothesis of $\mathrm{H}_{1}:\left\{\mathrm{a}_{1} \neq 0\right\} \mathrm{U}\left\{\mathrm{a}_{2} \neq 0\right\}$. In equation (2), the null hypothesis of no co-integration amongst the variables is $H_{0}: b_{1}=b_{2}=0$ against the alternative hypothesis of $\mathrm{H}_{1}:\left\{\mathrm{b}_{1} \neq 0\right\} \mathrm{U}\left\{\mathrm{b}_{2} \neq 0\right\}$. The null hypothesis can be tested with the $F$-test. The $F$-test has a non-standard distribution. Pesaran et al. (2001) provided the critical values at table CI (iii). At $k=1$, the critical values bounds are $\left(4.04,4.7^{8}\right)$ at the $10 \%$ level of significance, $(4.94,5.73)$ at the $5 \%$ level of significance, and $(6.84,7.84)$ at the $1 \%$ level of significance. To minimize the loss of degrees of freedom and to fulfil the assumption of no autocorrelation required by the ARDL test, the value of $n$ corresponding to each equation is increased until the Breusch-Godfrey Lagrange multiplier test is unable to reject the null of no autocorrelation with a lag order 1 at the $5 \%$ level of significance. The results of the bounds test are reported in Table 2.

Table 2.: The results of the bounds test for co-integration.

\begin{tabular}{|c|r|r|r|}
\hline \multicolumn{1}{|c|}{ Equation } & Ho & n & \multicolumn{1}{c|}{ F-Value } \\
\hline$(1)$ & $\mathrm{al}_{1}=\mathrm{a}_{2}=0$ & 1 & 3.0379 \\
$(2)$ & $\mathrm{b}_{1}=\mathrm{b}_{2}=0$ & 1 & 2.0241 \\
\hline
\end{tabular}

Source: Authors' calculation

Note: *, **, and ${ }^{* * *}$ indicate statistical significance at the $10 \%, 5 \%$ and $1 \%$ levels, respectively. The number of lags was selected based on the Schwarz Information Criteria.

The results in Table 2. indicate that we do not reject the null hypothesis of no cointegration at the $1 \%, 5 \%$, and $10 \%$ levels of significance for equations (1) and (2), respectively. Therefore, there is no long-run relationship between IFDI and DI when either IFDI or DI is assigned as the dependent variable. 
Table 3.: The results of the short-run Granger causality test.

\begin{tabular}{|c|c|c|}
\hline Dependent variable & $\Delta$ IFDI & $\Delta \mathrm{DI}$ \\
\hline$\Delta \mathrm{IFDI}$ & & $0.0245[0]$ \\
\hline$\Delta \mathrm{DI}$ & $-0.1176[3]$ & \\
\hline
\end{tabular}

Source: Authors' calculation

Note: *,**, and *** indicate statistical significance at the $10 \%, 5 \%$, and $1 \%$ levels, respectively. The number in square brackets is the value of $n$ selected based on either equation (1) or equation (2). The number of lags was selected based on Schwarz Information Criteria. IFDI: inward foreign direct investment; DI: direct investment.

$$
\begin{aligned}
& \Delta \mathrm{IFDI}_{t}=k_{0}+\sum_{i=1}^{n} k_{G i} \Delta \mathrm{IFDI}_{t-i}+\sum_{i=0}^{n} k_{F i} \Delta \mathrm{DI}_{t-i}+\sum_{i=0}^{n} k_{D i} \Delta \mathrm{EF}_{t-i}+\sum_{i=0}^{n} k_{O i} \Delta \mathrm{OPEN}_{t-i} \\
& +\sum_{i=0}^{n} k_{P i} \Delta \mathrm{CULTURE}_{t-i}+\sum_{i=0}^{n} k_{z i} \Delta \mathrm{SAVINGS}_{t-i}+k_{1} \mathrm{IFDI}_{t-1}+k_{2} \mathrm{DI}_{t-1}+k_{3} \mathrm{EF}_{t-1}+k_{4} \mathrm{OPEN}_{t-1}+k_{5}
\end{aligned}
$$

CULTURE $_{t-1}+k_{6}$ SAVINGS $_{t-1}+\varepsilon_{3 t}$

$$
\begin{aligned}
& \Delta \mathrm{DI}_{t}=m_{0}+\sum_{i=1}^{n} m_{F i} \Delta \mathrm{DI}_{t-i}+\sum_{i=0}^{n} m_{G i} \Delta \mathrm{IFDI}_{t-i}+\sum_{i=0}^{n} m_{D i} \Delta \mathrm{EF}_{t-i}+\sum_{i=0}^{n} m_{O i} \Delta \mathrm{OPEN}_{t-i} \\
& +\sum_{i=0}^{n} m_{P i} \Delta \text { CULTURE }_{t-i}+\sum_{i=0}^{n} m_{z i} \Delta \mathrm{SAVINGS}_{t-i}+m_{1} \mathrm{DI}_{t-1}+m_{2} \mathrm{IFDI}_{t-1}+m_{3} \mathrm{EF}_{t-1}+m_{4} \mathrm{OPEN}_{t-1}+
\end{aligned}
$$$$
m_{5} \text { CULTURE }_{t-1}+m_{6} \text { SAVINGS }_{t-1}+\varepsilon_{4 t}
$$

In equation (3), the null hypothesis of no co-integration amongst the variables is $\mathrm{H}_{\circ}: k_{1}=k_{2}=k_{3}=k_{4}=k_{5}=k 6=0$ against the alternative hypothesis of $\mathrm{H}_{1}:\left\{\mathrm{k}_{1} \neq \mathrm{O}\right\} \mathrm{U}\left\{\mathrm{k}_{2} \neq \mathrm{O}\right\} \mathrm{U}$ $\left\{\mathrm{k}_{3} \neq 0\right\} \mathrm{U}\left\{\mathrm{k}_{4} \neq 0\right\} \mathrm{U}\left\{\mathrm{k}_{5} \neq 0\right\} \mathrm{U}\left\{\mathrm{k}_{6} \neq 0\right\}$. In equation (4), the null hypothesis of no co-integration amongst the variables is $\mathrm{H}_{0}: m_{1}=m_{2}=m_{3}=m_{4}=m_{5}=m_{6}=0$ against the alternative hypothesis of $\mathrm{H}_{1}:\left\{\mathrm{m}_{1} \neq \mathrm{O}\right\} \mathrm{U}\left\{\mathrm{m}_{2} \neq \mathrm{O}\right\} \mathrm{U}\left\{\mathrm{m}_{3} \neq \mathrm{O}\right\} \mathrm{U}\left\{\mathrm{m}_{4} \neq \mathrm{O}\right\} \mathrm{U}\left\{\mathrm{m}_{5} \neq \mathrm{O}\right\} \mathrm{U}\left\{\mathrm{m}_{6} \neq \mathrm{O}\right\}$. From the table CI(iii) of Pesaran et al. (2001), at $\mathrm{k}=5$ the critical bounds are $(2.26,3.35)$ at the $10 \%$ level of significance, $(2.62,3.79)$ at the $5 \%$ level of significance, and $(3.41,4.68)$ at the $1 \%$ level of significance. Similarly, the value of $n$ in each equation is determined by the Breusch-Godfrey Lagrange multiplier test. The results of the bounds test in multivariate model are reported in Table 4 . 
Table 4.: The results of the bounds test for co-integration.

\begin{tabular}{|l|r|r|r|}
\hline Equation & Ho & n & \multicolumn{1}{c|}{ F-value } \\
\hline$(3)$ & $k_{1}=k_{2}=k_{3}=k_{4}=k_{5}=0$ & 2 & $7 \cdot 4618^{* * * * *}$ \\
$(4)$ & $\mathrm{m}_{1}=\mathrm{m}_{2}=\mathrm{m}_{3}=\mathrm{m}_{4}=\mathrm{m}_{5}=0$ & & 2 \\
\hline
\end{tabular}

Source: Authors' calculation

Note: *,**, and *** indicate statistical significance at the $10 \%, 5 \%$, and $1 \%$ levels, respectively.

The results in Table 4 . show that the null hypothesis of no co-integration is rejected at the $1 \%$ level for equation (3) and (4). It is clear that with the presence of control variables, there is a long-run relationship between IFDI, DI, EF, OPEN, CULTURE and SAVINGS, when DI or IFDI is assigned as the dependent variable. To obtain the long-run coefficients, the ARDL model is estimated as shown here:

$$
\begin{aligned}
& \left(1-c_{l} L-\ldots-c_{p} L^{p}\right) \mathrm{IFDI}_{t}=d_{0}+\left(1-d_{1} L-\ldots-d_{q} L^{q}\right) \mathrm{DI}_{t}+\left(1-f_{l} L-\ldots-f_{s} L^{s}\right) \mathrm{EF}_{t}+(1- \\
& \left.h_{1} L-\ldots-h_{j} L^{j}\right) \mathrm{OPEN}_{t}+\left(1-e_{l} L-\ldots-e_{r} L^{\prime}\right) \mathrm{CULTURE}_{t}+\left(1-k_{l} L-\ldots-k_{g} L^{g}\right) \mathrm{SAVINGS}_{t}+\varepsilon_{5 t}
\end{aligned}
$$

$$
\begin{aligned}
& \left(1-\theta_{1} L-\ldots-\theta_{u} L^{u}\right) \mathrm{DI}_{t}=\phi_{0}+\left(1-\phi_{1} L-\ldots-\phi_{v} L^{v}\right) \mathrm{IFDI}_{t}+\left(1-\alpha_{1} L-\ldots-\alpha_{x} L^{x}\right) \mathrm{EF}_{t}+(1- \\
& \left.\beta_{1} L-\ldots-\beta_{y} L^{y}\right) \mathrm{OPEN} t+\left(1-\gamma_{1} L-\ldots-\gamma_{z} L^{z}\right) \mathrm{CULTURE}_{t}+\left(1-\gamma_{1} L-\ldots-\gamma_{h} L^{h}\right) \mathrm{SAVINGS}_{t}+\varepsilon_{6 t}
\end{aligned}
$$

The Optimal lags of the ARDL model are chosen based on Schwarz information criteria. Because of small sample size and annual data used in this study, the maximum possible values of $u, v, x, y$, and $z$ in equation (6) are set at 2 . The selected values of $u, v, x, y, z$ and $h$ are 2,2, 1, 2,2, and 2, respectively. The maximum possible values of $p, q, s, j$, rand $g$ are also set at 2 in equation (5) and selected values of $p, q, s, j, r$ and $g$ are $1,2,1,0,1$, and 2 , respectively in equation (5). The reparametrized equation (5) and equation (6) with long-run coefficients is reported in Table 5 . The statistically significant and negative long-run coefficient of the independent variable (IFDI) indicates that IFDI has negative effects on DI (Dependent variable) in equation (6). The long-run coefficient of formal institutions (EF) has significant and positive effects on domestic investment (DI) but long run coefficient of informal institutions (CULTURE) has insignificant effects on domestic investment (DI). The long-run coefficients of SAVINGS and OPEN (trade openness) have significant effects on DI.SAVINGS are positively associated with DI and OPEN (trade openness) is negatively correlated with DI in the long run. The long-run coefficient of independent variable (DI) indicates that DI has insignificant effects on IFDI (Dependent variable) in equation (5). The control variables in the model such as EF, OPEN, GULTURE and SAVINGS have also insignificant effects on IFDI (dependent variable) in equation (5). 
Table 5.: Estimated long-run coefficients.

\begin{tabular}{|l|r|r|}
\hline & \multicolumn{2}{|c|}{ Dependent variable } \\
\hline Constant & IFDI & DI \\
IFDI & $20.4729(0.8208)$ & $-7.755^{* * *}(-3.7920)$ \\
DI & & $-0.464 .2(-1.4 .879)$ \\
EF & $1.5^{388}(0.7414)$ & \\
OPEN & $-4.9511(-0.8784)$ & $0.99^{3} 9^{* * *}(3.2568)$ \\
CULTURE & $0.0961(0.4557)$ & $-0.2159^{* * *}(-7.9061)$ \\
SAVINGS & $1.5788(0.4635)$ & $-0.2704(-0.6434)$ \\
\hline
\end{tabular}

Source: Authors' calculation

Note: *,**, and ${ }^{* * *}$ indicate statistical significance at the $10 \%, 5 \%$, and $1 \%$ levels, respectively. T-ratios are given in parentheses.

Based on the results of the bounds test in the multivariate framework, the Granger causality tests are implemented in the models shown here:

$$
\begin{aligned}
& \Delta \mathrm{IFDI}_{t}=q_{0}+\sum_{i=1}^{n} q_{\mathrm{Gi}} \Delta \mathrm{DI}_{t-i}+\sum_{i=0}^{n} q_{F i} \Delta \mathrm{IFDI}_{t-i}+\sum_{i=0}^{n} q_{D i} \Delta \mathrm{EF}_{t-i}+\sum_{i=0}^{n} q_{O i} \Delta \mathrm{OPEN}_{t-i} \\
& +\sum_{i=0}^{n} q_{\mathrm{Pi}} \Delta \mathrm{CULTURE}_{t-i}+\sum_{i=0}^{n} q_{\mathrm{wi}} \Delta \mathrm{SAVINGS}_{t-i}++\tau \mathrm{ECT}_{q t-l}+\varepsilon 7 t
\end{aligned}
$$

$$
\begin{aligned}
& \Delta \mathrm{DI}_{t}=p_{0}+\sum_{i=1}^{n} p_{\mathrm{Gi}} \Delta \mathrm{DI}_{t-i}+\sum_{i=0}^{n} p_{F i} \mathrm{\Delta IFDI}_{t-i}+\sum_{i=0}^{n} p_{D i} \Delta \mathrm{EF}_{t-i}+\sum_{i=0}^{n} p_{O i} \Delta \mathrm{OPEN}_{t-i} \\
& +\sum_{i=0}^{n} p_{\mathrm{Pi}} \Delta \mathrm{CULTURE}_{t-i}+\sum_{i=0}^{n} p_{y i} \Delta \mathrm{SAVINGS}_{t-i}+\gamma \mathrm{ECT}_{p t-1}+\varepsilon_{8 t}
\end{aligned}
$$

(8)

$\mathrm{EGT}_{q t-1}(7)$ and $\mathrm{ECT}_{p t-1}(8)$ are the error correction terms. A significant error correction coefficient indicates that long-run Granger causality from the independent to the dependent variables, where long-run Granger non-causality is regarded as equivalent. Similarly, the Breusch-Godfrey Lagrange multiplier test is again used to determine the value of $n$ in each equation. The results show that there is long run unidirectional causality running from IFDI to DI in equation (8) as coefficient of error correction term is negative and insignificant as reported in Table 6. 
Table 6.: Results of Granger's causality test: long-run.

\begin{tabular}{|c|c|}
\hline Equation & Coefficient of error correction term \\
\hline （ $)$ & $-0.15^{20} 079(-0.8213)$ \\
\hline (8) & $-1.519144^{* * * *}(-8.6696)$ \\
\hline
\end{tabular}

Source: Authors' calculation

Note: ***, and *** indicate statistical significance at the $10 \%, 5 \%$, and $1 \%$ levels, respectively. T-ratios are given in parentheses.

We have used the approaches of Ram (1988) and Zhang (2001) to determine the sign of the short-run Granger causality. The sign of the short-run Granger causality from an independent variable to dependent variable is determined by adding up the coefficients of all lagged first differences of the independent variable. The results of the short-run Granger causality test are reported in Table 7 . Based on the F-test, we cannot find evidence to support the existence of short-run Granger causality between IFDI and DI.

Table 7.: The results of the short-run Granger causality test.

\begin{tabular}{|l|r|r|}
\hline \multicolumn{1}{|c|}{ Dependent variable } & $\Delta$ IFDI & \multicolumn{1}{c|}{$\Delta$ DI } \\
\hline$\Delta$ IFDI & & $-0.764[2]$ \\
$\Delta$ DI & $0.234[2]$ & \\
\hline
\end{tabular}

Source: Authors' calculation

Note: ***, and ${ }^{* * *}$ indicate statistical significance at the $10 \%, 5 \%$, and $1 \%$ levels, respectively. The number in square brackets is the value of $n$ selected based on either equation (7) or (8). The number of lags is selected based on the Schwarz Information Criteria.

\section{CONCLUDING REMARKS}

This paper examined the short- and long-run relationship between IFDI and DI with bivariate and multivariate frameworks and analyses relationship between Inward FDI and domestic investment in China, using co-integration and Granger causality analysis (Including bivariate and multivariate Granger causality models). We have applied auto-regressive distributed lags (ARDL) technique to derive relationship between inward FDI and domestic investment using time series data for China. The obtained results in the bivariate model conclude that there is no short- and longrun relationship between IFDI and DI, using Granger causality analysis. Bivariate model results can be unreliable due to the omission of important control variables. Thus, important control variables are paramount in the model to derive unbiased and reliable findings. Siliverstovs and Herzer (2006) explain that the results of Granger causality tests may not be valid if the model suffers from the omission of important independent variables. However, after controlling for country-specific effects (i.e., with the inclusion of EF, OPEN, CULTURE, SAVINGS) in the multivariate frame- 
work, the results of the multivariate model show that there is positive unidirectional causal relationship from IFDI to DI in the long run. In the short-run, DI and IFDI do not allow Granger causality. It implies that the bivariate framework is miss-specified in terms of omitting important independent variables. Here, we analyzed the macroeconomic impact of FDI inflows on DI for a strongly emerging Chinese economy. From our dataset, we find when FDI inflows increase, DI also behaves in similar way, which also strongly aligns with our econometric findings that there is positive, longrun, unidirectional causality running from IFDI to DI. Our findings instead strongly support that the idea that increased IFDI is the cause of increased DI in the long-run. 


\section{REFERENCES}

Alabdeli, A. "Expectation of the impact of exports on economic growth in developing countries: An Econometric and Analytical study." Al-Azhar University. Saleh Salem Centre Journal for Islamic Economy. 9 th year 27 (2005): 215-259

Agosin, Manuel R., and Roberto Machado. "Foreign investment in developing countries: does it crowd in domestic investment?." Oxford Development Studies 33, no. 2 (2005): 149-162

Andersen, Palle Schelde, and Philippe Hainaut. Foreign direct investment and employment in the industrial countries. No. 61. Bank for International Settlements, Monetary and Economic Department, 1998.

Arndt, Christian, Claudia M. Buch, and Monika E. Schnitzer. "FDI and domestic investment: an industrylevel view." The BE Journal of Economic Analysis \& Policy 10, no. 1 (2010)

Alsadiq, Ali. "Outward foreign direct investment and domestic investment: The case of developing countries." (2013)

Bayraktar, Saglam B. Yasemin, Yalta A., "Dynamic linkages among Foreign direct investment, Public investment and Private investment: Evidence from Turkey", Applied Econometrics and International Development Vol. 11-2 (2011): 71-82

Blejer, M. I., \& Khan, M. S. Government Policy and Private Investment in Developing Countries (Politique des pouvoirs publics et investissement privé dans les pays en développement)(Política estatal e inversión privada en los países en desarrollo). Staff Papers-International Monetary Fund, (1984): 379-4,03

Buckley, P.J., Clegg, J., \& Wang,C., The impact of inward FDI on the performance of Chinese manufacturing firms, Journal of International Business Studies, 33(4), (2002): 637-655

Chakraborty, C., \& Basu, P. Foreign direct investment and growth in India: a cointegration approach. Applied Economics, 34, (2002): 1061-1073

Chang, S. C., Estimating relationships among FDI inflow, domestic capital, and economic growth using the threshold error correction approach. Emerging Markets Finance and Trade, 46, (2010): 6-15

Dickey, D. A., \& Fuller, W. A., Distributions of the estimators for autoregressive time series with a unit root. Journal of the American Statistical Association, 74, (1979): 427-4,31

Dickey, D. A., \& Fuller, W. A.,.Likelihood ratio statistics for autoregressive time series with a unit root, Econometrica, 49, (1981): 1057-1072

Dunning, J.H., Van Hoesel, R., \& Narula, R. Third world multinationals revisited: new developments and theoretical implications. In: J. H. Dunning (Ed.), Globalization, Trade and Foreign Direct Investment Oxford: Pergamon Press. (1998): 255-286

Derado Dražen, "Determinants of Foreign direct investment in transition economies and evaluation of their potential in Croatia", Institute for Public Finance, Selected translations ISSN $1847^{-} 7445$ No. $17 / 13$ : (2013): 1 - 29

Fukasaku, K., Wall, D., \& Wu, M. (1994). China's long march to an open economy. Paris: Development Centre of the Organisation for Economic Co-operation and Development. Feldstein, M. (1994). The effects of outbound foreign direct investment on the domestic capital stock. National Bureau of Economic Research Working Paper No. 4668.

Frankel, J. (1997). Determinants of Long Term Growth. Available online at: http://ksghome.harvard. edu/ jfrankel/Apecgrow.PDF (Accessed on 15 th May 2009) 
Goh, S.K. and Wong, K.N., Outward FDI and domestic investment. International Proceedings of Economics Development and Research, 55.27, (2012): 137-14.0

Greene, J., \& Villanueva, D., Private investment in developing countries: an empirical analysis. Staff Papers-International Monetary Fund, (1991): 33- $5^{8}$

Herzer, D., Klasen, S., \& Nowak-Lehmann, D. F., In search of FDI-led growth in developing countries: The way forward. Economic Modelling, 25(5), (2008): 793-810

Hejazi, W., \& Pauly, P., Motivations for FDI and domestic capital formation. Journal of International Business Studies, 34,(3), (2003): 282-289

Herzer, D., The long-run relationship between outward FDI and domestic output: Evidence from panel data. Economics Letters, 100, (2008): 146-14.9

Herzer, D., \& Schrooten, M., Outward FDI and domestic investment in two industrialized countries. Economics Letters, 99, (2008): 139-143

Hansen, H. \& Rand, J., On the Causal Links between FDI and Growth in Developing Countries. The World Economy, 29, (2006): 21-41

Im, K.S., Pesaran, M.H., \& Shin, Y., Testing for unit roots in heterogeneous panels. Journal of Econometrics, 115, (2003): $5^{3-74}$

Kwiatkowski, D., Peter, C. B. P., Schmidt, P., \& Shin, Y., Testing the null hypothesis of stationaryagainst the alternative of a unit root. Journal of Econometrics, 54, (1992): 159-178

Lean, Hooi Hooi, and Bee Wah Tan. "Linkages between foreign direct investment, domestic investment and economic growth in Malaysia." Journal of Economic Cooperation \& Development 32, no. 4 ( 2011): 75

Persidangan Kebangsaan Ekonomi Malaysia keV (PERKEM V): 48-57dy, N. R. (1994). China in the world economy. Washington,D.G.: Institute for International Economics.

Lee, Il Houng, Murtaza Syed, and Liu Xueyan. "China's path to consumer-based growth: Reorienting investment and enhancing efficiency." (2013)

Lee, Chew Ging. "Outward foreign direct investment and economic growth: Evidence from Japan." Global Economic Review 39, no. 3 (2010): 317-326

Levin, Andrew, Chien-Fu Lin, and Chia-Shang James Chu. "Unit root tests in panel data: asymptotic and finite-sample properties." Journal of econometrics 108, no. 1 (2002): 1-24

Lim, Mr Ewe-Ghee. Determinants of, and the relation between, foreign direct investment and growth: a summary of the recent literature. No. 1-175. International Monetary Fund, 2001

Liu, Xiaohui, Peter Burridge, and Paul JN Sinclair. "Relationships between economic growth, foreign direct investment and trade: evidence from China." Applied economics 34, no. 11 (2002): 14,33-144.0

MOFCOM (2014). Ministry of commerce of China. Retrieved from http://english.mofcom.gov.cn

Naughton, Barry, ed. The China circle: Economics and technology in the PRC, Taiwan, and Hong Kong. Brookings Institution Press, 2012

Ndikumana, Leonce. "Financial determinants of domestic investment in Sub-Saharan Africa: Evidence from panel data." World Development 28, no. 2 (2000): 381-4,00

Prasanna, N. ,"Direct and Indirect Impact of Foreign Direct Investment (FDI) on Domestic Investment (DI) in India", J Economics, 1(2) (2010): 77-83 
Pedroni, Peter. "Critical values for cointegration tests in heterogeneous panels with multiple regressors." Oxford Bulletin of Economics and statistics 61, no. S1 (1999): 653-670

Pesaran, M. Hashem, and Yongcheol Shin. "An autoregressive distributed-lag modelling approach to cointegration analysis." Econometric Society Monographs 31 (1998): 371-413

Pesaran, M. Hashem, Yongcheol Shin, and Richard J. Smith. "Bounds testing approaches to the analysis of level relationships." Journal of applied econometrics 16, no. 3 (2001): 289-326

Phillips, Peter CB, and Pierre Perron. "Testing for a unit root in time series regression." Biometrika 75, no. 2 (1988): $335-34,6$

Ram, Rati. "Additional evidence on causality between government revenue and government expenditure." Southern Economic Journal (1988): 763-769

Sauramo, P. (2008). Does Outward Foreign Direct Investment Reduce Domestic Investment. Discussion Paper 239, Labor Institute for Economic Research [online] http://www. labour. fi/tutkimusjulkaisut/ tyopaperit/sel239. pdf (accessed 5 March 2010)

Siliverstovs, Boriss, and Dierk Herzer. "Export-led growth hypothesis: evidence for Chile." Applied Economics Letters 13, no. 5 (2006): 319-324

Stevens, G. V., \& Lipsey, R. E., Interactions between domestic and foreign investment. Journal of international money and finance, 11(1), (1992): 4,0-62

Sağlam, B. B., \& Yalta, A. Y., Dynamic linkages among foreign direct investment, public investment and private investment: Evidence from Turkey. Applied Econometrics and International Development, 11, (2011): $71-82$

UNCTAD. (2013). Foreign direct investment. Retrieved from http://unctadstat.unctad.org/ ReportFolders/reportFolders.aspx?sRF_ActivePath $=\mathrm{P}, 5,27 \& s R F \_$Expanded $=\mathrm{P}_{5}$

UNCTAD (2015).World Investment Report. Washington DC: World Bank.

Wai, T.U., \& Wong, C.H., Determinants of Private Investment in Developing countries.Journal of Development Studies, 19(1), (1982): 19-36

Wang, M., Foreign direct investment and domestic investment in the host country: Evidence from panel study. Applied Economics, 42, (2010): 3711-3721

You, K., \& Solomon, O. H., China's outward foreign direct investment and domestic investment: An industrial level analysis. China Economic Review, (2015): 1-39

Zhang, K.H., Does foreign direct investment promote economic growth? Evidence from East Asia and Latin America. Contemporary Economic Policy, 19, (2001): 175-185

$\mathrm{Xu}, \mathrm{G} .$, \& Wang, R., The effect of foreign direct investment on domestic capital formation, trade, and economic growth in a transition economy: Evidence from China. Global Economy Journal, 7, (2007): 1-21 